\title{
Razoabilidade e proporcionalidade na tutela jurisdicional dos direitos humanos
}

\author{
Yvete Flávio da Costa \\ yvete@netsite.com.br \\ Doutorado em Direito pela Pontifícia \\ Universidade Católica de \\ São Paulo, Brasil \\ Professor Assistente Doutor da \\ Universidade Estadual Paulista Júlio de \\ Mesquita Filho.
}

Vinicius Fernandes Ormelesi

viniciusormelesi@hotmail.com

Especialização em Docência do Ensino

Superior pela Faculdade de Educação

São Luís, Brasil

Professor Voluntário de Serviço de

Extensão da Universidade Estadual

Paulista Júlio de Mesquita Filho.

Recebido em 26/08/2011

Aprovado em 23/02/2012

\section{Resumo}

O presente trabalho se insere no contexto da problemática relativa aos direitos humanos, principalmente no que tange à sua exigibilidade e aplicação. Em igual medida, o estudo se vincula, dentro de um recorte epistemológico necessário, à questão da tutela jurisdicional desses direitos. Para desenvolver a investigação, utiliza-se de um exame detido e angular acerca da posição metodológica e científica dos princípios jurídicos dentro do direito. De posse dessas indagações, é possível ponderar o conjunto de diretrizes, normas, princípios e costumes que se convencionou chamar de direitos humanos. Faz-se uma incursão na origem dos direitos humanos,

bem como se avalia os atributos teóricos e práticos que eles ganharam no passar do tempo, tendo-se em vista a historicidade do fenômeno jurídico. Quando chegado o momento de se discutir a aplicabilidade da tutela jurisdicional dos direitos humanos, são invocados dois princípios para servirem de lastro. Postula-se, assim, pelo dimensionamento da tutela com base na razoabilidade e na proporcionalidade.

\section{Palavras-chave}

princípios jurídicos; tutela jurisdicional; direitos humanos; razoabilidade; proporcionalidade. 


\title{
Reasonableness and proportionality in judicial protection of human rights
}

\author{
Yvete Flávio da Costa \\ Vinicius Fernandes Ormelesi
}

Abstract

This work forms part of the problem concerning buman rights, especially respecting its enforceability and enforcement. Also, the study links, within a required epistemological clipping, the question of judicial protection of those rights. To develop the research, it uses an examination held and angle about the methodological and scientific position about legal principles in the law. Possessing these quests, we can consider the set of guidelines, standards, principles and customs that naturalized buman rights. A foray into the origin of human rights, as well as assessing the practical and theoretical attributes that they have won over the time, having in mind the legal phenomenon of historicity. When the time has come to discuss the applicability of judicial protection of human rights, are invoked two principles to serve as ballast. Thus it postulates by a dimension of the legal treatment in reasonableness and in proportionality as principles.

Key words

legal principles; judicial protection; buman rights; reasonableness; proportionality. 


\section{Sumário}

Introdução

1 Princípios jurídicos

1.1 Princípios, valores e regras

1.2 Distinção entre princípios e valores

1.3 Distinção entre princípios e regras

2 Razoabilidade e proporcionalidade

3 Direitos humanos

4 Tutela jurisdicional e aplicação dos princípios

4.1 Tutela penal dos direitos humanos

4.2 Tutela coletiva dos direitos humanos

Conclusão

Referências bibliográficas 


\section{Introdução}

Tutelar direitos humanos sob o prisma jurisdicional é uma grande ideia e uma angústia ao mesmo tempo. A questão se avulta no cenário internacional, no qual são frequentes as violações aos direitos humanos, sobretudo em tempos de guerra. Não bastasse isso, pelo cerne da questão ainda passam as diferenças culturais entres os povos, acentuadamente entre as tradições ocidentais eurocêntricas e as orientais do médio e extremo oriente.

Os romanos sempre tiveram a noção de que não há direito sem juízes que o digam, sendo para eles indissociável o jus do juris dictio ${ }^{1}$.. Se a justiça é atribuir a cada um a sua parte, sendo justo o homem que toma para si nem mais nem menos do que merece, o que fazer quando ainda está longe de ser efetiva uma jurisdição internacional que dê a cada um o que é seu e quando ainda não se sabe qual a parte de cada um?

\section{Princípios jurídicos}

Na pós-modernidade, principalmente depois das teorias de Alexy e Dworkin, a doutrina tem se preocupado em fazer a distinção entre princípios e regras. Isso reflete uma superação do positivismo clássico, que já vinha sendo questionado pelo constitucionalismo emergente das declarações de direitos fundamentais e das cartas constitucionais dos países no pós-guerra. Evidentemente, a concepção do direito com base nos princípios, representa uma ruptura com as tradições e inaugura uma nova etapa da metodologia do direito. "O Estado contemporâneo [...] não dispensa a conformação das regras aos princípios constitucionais e sabe que isso somente pode ser feito com o auxílio da jurisdição."’2

\subsection{Princípios, valores e regras}

Nos Estados de Direito é notória a presença de princípios constitucionais que fundamentam a ordem jurídica estatal com as exigências morais e éticas relevantes para a comunidade. Esse fenômeno é marcado pela inserção nas cartas políticas das nações de princípios e valores.

1 VILLEY. Michel. O direito e os direitos humanos. Trad.. Maria Ernestina de Almeida Prado Galvão. São Paulo: Martins fontes, 2007, p. 43

2 MARINONE, Luiz Guilherme. Teoria Geral do Processo - curso de processo civil. São Paulo: RT. 2006, V. 1, p.50 
A Constituição Federal Brasileira de 1988 também foi influenciada por este constitucionalismo do pós-guerra, em reação à decadência de regimes autoritários, assim como as Constituições portuguesa de 1976, alemã de 1949 e italiana de 1948. A carta magna do Brasil consagra em seu preâmbulo os valores supremos da sociedade brasileira, tal como a liberdade, a segurança, o desenvolvimento, a igualdade, a justiça etc., encontrando expressão normativa através de princípios e regras distribuídos ao longo do texto constitucional.

No bojo das normas constitucionais, sobretudo naquelas que dispõem sobre direitos fundamentais, encontra-se alto teor valorativo, na medida em que traduzem para a linguagem normativa os valores supremos da sociedade.

Nesta seara, torna-se imprescindível o exame detido e aprofundado das normas, princípios e valores. Nosso trabalho encabeça uma divagação teórica acerca da principiologia, razão pela qual não podemos preterir uma conceituação jurídica dos princípios, e ela, assim cremos, só se concretiza quando se têm nítidas as semelhanças e principalmente as diferenças entre esses três entes.

Deste modo, devemos cuidar da questão em duas etapas. Primeiramente, faremos a distinção entre valores e princípios, com base nas teorias de Alexy, Peczenik, Reale e Habermas e, logo em seguida, entre princípios e regras, para, ao final, considerarmos uma possibilidade de distinção entre princípios e normas, igualmente pautando-nos nas considerações de Larenz, Dworkin e Alexy.

\subsection{Distinção entre princípios e valores}

Costuma-se partir do pressuposto de que valores são semelhantes a bens e, justamente em virtude disso, podem ser ponderados. Não está de todo errada essa afirmação, porém, os valores são bem mais do que isso. Max Scheler, ${ }^{3}$ baseando-se na fenomenologia de Edmund Husserl, afirma que os valores habitam o imo emocional do homem, que se traduzem na experiência emocional formadora de unidades fenomenais determinantes da consciência e das atitudes.

O principal problema que se identifica é a confusão existente entre o que se entende por valor e o que se entende por princípio. Tal limbo terminológico se justifica pelas semelhanças entre os dois, como bem salienta Alexy: ${ }^{4}$ tanto princípios como valores podem colidir e serem concretizados de forma gradual.

3 SCHELER, Max. A reviravolta de valores. Trad. Marco Antonio dos Santos Casanova. Petrópolis: Vozes, 1994, p. 43-44

4 ALEXY, Robert. El concepto y la validez del derecho. Barcelona: Gedisa, 2004, p. 64 
A solução que Alexy propõe se assenta no plano conceitual lógico. Ele infere estarem os princípios relacionados a mandamentos, diretrizes, proibições e permissões, habitando o mundo do dever-ser, sendo, portanto, deontológicos por natureza. Os valores, ao contrário, expressam mais a ideia de bom, ligados à certeza, segurança, beleza, ficando no plano dos conceitos axiológicos. Haveria ainda o plano antropológico, no qual estariam a vontade e o interesse, por exemplo.

Destarte, no campo deontológico estão as regras e os princípios, como espécies do gênero norma, caracterizados pela tônica do dever ser, sendo verdadeiros mandamentos (as regras mandados definitivos e os princípios mandados de otimização), no nível axiológico a separação se dá entre regras de valoração (que não podem ser objeto de ponderação) e valores (que podem ser objeto de ponderação). ${ }^{5}$

Dessa maneira, a diferenciação fundamental, segundo Alexy, é uma questão semântica, significando os princípios aquilo que é devido e os valores aquilo que é melhor. Nesse sentido, também caminha a concepção de Peczenik. ${ }^{6}$ Para ele, os valores se aproximam do conceito de ideais. É ínsito aos valores o juízo de ponderação moral, podendo ser individuais, sociais, religiosos. Os princípios, ao seu turno, proclamam valores, enquanto as regras determinam condutas e compromissos entre valores.

Todavia, Peczenik não inova muito na acepção de Alexy e acaba por concluir, como este, que a diferença principal entre princípios e valores reside nos planos deontológico e axiológico. Os princípios possuem caráter de obrigatoriedade e os valores de bem, útil e melhor.

Para Miguel Reale, ${ }^{7}$ a categoria valor constitui-se num dos pressupostos da experiência jurídica efetivada pela teoria da tridimensionalidade. $\mathrm{O}$ autor esclarece serem os valores bens, materiais ou espirituais, criados pelo homem no decorrer da história. As valorações são consubstanciações de interesses, através dos quais a atividade humana procura satisfazer a vontade presente num valor, impedindo que um não-valor possa se sobrepor àquele.

5 LAEXY, Robert. Teoria de los derechos fundamentales. Madrid: Centro de Estúdios Políticos y Constitucionales, 2001, p. 145.

6 PECZENIK, Aleksander. Law, morality, coherence and truth. A Theory of legal doctrine. Pp 146-176. In: Ratio Juris, v. 14, n. 1, March, 2001, p. 75-105..

7 REALE, Miguel. Filosofia do Direito. 20 ed. São Paulo: Saraiva, 2002, p. 543 
Resta mencionar a visão de Habermas. Ele aceita a colocação dos princípios no patamar deontológico, mas estabelece que os valores são principalmente teleológicos. Deste modo, os princípios, como normas, se subsumem em válidos ou inválidos antagonicamente, a revelia do que ocorre com os valores, que podem ser ponderados gradualmente. ${ }^{8}$

Outro aspecto importante sobre os princípios é o caráter absoluto que carregam. Em contraposição, os valores não pretendem ser absolutos, apenas orientando o que seja mais benéfico dentro de um agrupamento humano. Em última análise, os princípios não permitem contradições, no sentido de se complementarem, ao passo que os valores visam prevalecer uns sobre os outros. ${ }^{9}$

\section{3 distinção entre princípios e regras}

A separação conceitual entre regras e princípios possui relevante importância no âmbito das discussões acerca dos direitos fundamentais. Por isso mesmo, tal divisão se encontra presente no âmago das disciplinas de direito público que pretendam um aprofundamento teórico maior. ${ }^{10}$

A fim de posicionar a questão, analisaremos a teoria de Karl Larenz. Para ele, os princípios não são normas, mas sim critérios e fundamentos para consolidação de uma norma. Os princípios não são regras por lhes faltar o caráter formal de proposições jurídicas, de modo que se apresentam como diretrizes. Desse modo, os princípios se prestam a estabelecer parâmetros para a feitura e interpretação das regras jurídicas num ideal de obtenção do Direito Justo. ${ }^{11}$

Passemos a expor as considerações de Ronald Dworkin. ${ }^{12}$ Conforme o seu pensamento, a distinção entre regras e princípios não se dá no plano lógico ou qualitativo, uma vez que ambos fornecem critérios para a solução de casos concretos nas decisões judiciais. As regras seguem a lógica disjuntiva, ou são válidas e se aplicam ou não são e não se aplicam. A análise é feita conforme o enunciado da regras,

8 HABERMAS, Jürgen. Direito e Democracia: entre facilidades e validade. Trad. Rio de Janeiro: Tempo Brasileiro, 1997, p. 328

9 HABERMAS, Jürgen. Direito e Democracia: entre facilidades e validade. Trad. Rio de Janeiro: Tempo Brasileiro, 1997, p. 329

10 ÁVILA, Humberto. Teoria dos princípios: da definição à aplicação dos princípios jurídicos. 4 ed. São Paulo: Malheiros, 2004, p. 18

11 LARENZ, Karl. E1 Derecho Justo: fundamentos de ética jurídica. 2 ed. Madrid: Civitas, 2002, p. 33-35

12 DWORKIN, Ronald. Levando os direitos a sério: Trad. Nelson Pereira. São Paulo: Martins Fontes, 2002 
abarca ou não o contexto dos fatos. No caso dos princípios não, Dworkin admite que os princípios possam ser apreciados segundo sua importância, inclusive pelo julgador. Outra consideração deste autor é no tocante à possibilidade de regras se assemelharem a princípios, quando trazem em seus enunciados e dispositivos conceitos indeterminados. ${ }^{13}$

Em grande contraste com a tese de Dwokin, caminhou a teoria de Robert Alexy. A primeira objeção que Alexy levanta é que a concepção de Dworkin não permite averiguar como se dá o conflito entre princípios e como ele se resolve. Ele admite que o conflito de regras gera uma mútua exclusão e o entre princípios é permeado por dimensões valorativas. Alexy estatui três fases de análise em sua teoria principiológica: a tese da otimização; a lei da colisão; e a lei da ponderação. ${ }^{14}$

Neste viés, são os princípios mandados de otimização, que devem ser cumpridos de forma a realizar o máximo que as possibilidades fáticas e jurídicas permitam. Portanto, no que se refere à tese da otimização, as teses de Alexy e Dworkin se complementam, já que o primeiro também admite que uma norma ou é um princípio ou é uma regra. A grande diferença se dá no plano da lei de colisões. Para Alexy, a colisão de regras jurídicas com dispositivos antagônicos se resolve por simples aplicação de ferramentas hermenêuticas. ${ }^{15}$. O conflito de princípios se decide com um dando lugar ao outro sem que perca sua incidência ou validade, mas meramente segundo a conveniência do caso concreto. Isso já nos conduz à última tese de Alexy quanto à ponderação, a qual reflete uma conexão entre a teoria dos princípios e o princípio da proporcionalidade. ${ }^{16}$

Antes de finalizar, convém fazer menção aos estudos do professor Humberto Ávila ${ }^{17}$ (2004: 78-79) que, no cenário nacional, representa a síntese entre as teorias normativas dos princípios. Em suas palavras, eles seriam

[...] normas imediatamente finalísticas, primariamente prospectivas e com pretensão de complementaridade e de parcialidade, para cuja aplicação se demanda uma avaliação da correlação entre o estado de coisas a ser promovido e os efeitos decorrentes da conduta havida como necessária a sua promoção.

13 DWORKIN, Ronald. Uma questão de princípios. São Paulo: Martins Fontes. 2001

14 ALEXY, Robert. On the sctructure of legal principles. In Ratio Júris, v. 13, setembro, 2000.

15 MAXimiliano, Carlos. Hermenêutica e Aplicação do Direito. 11 Ed. Rio de Janeiro: Forense, 1990.

16 Conf. ÁVILA, Humberto. Teoria dos princípios: da definição à aplicação dos princípios jurídicos. 4 ed. São Paulo: Malheiros, 2004.

17 ÁVILA, Humberto. Teoria dos princípios: da definição à aplicação dos princípios jurídicos. 4 ed. São Paulo: Malheiros, 2004, 78-79 
Encerramos nossa exposição das principais teorias acerca do tema, com a consideração de que, no atual contexto e estágio metodológico do Direito, o fato de o princípio assumir a condição de norma representa inquestionável avanço teórico. Antes, os princípios gozavam apenas de juridicidade, assim como os costumes, com o pós-positivismo, ganham a normatividade, passando a ser considerados na ciência do Direito com o respeito e o status que merecem.

\section{Razoabilidade e proporcionalidade}

Tal qual a aproximação entre as deusas gregas Themis e Diké, que os séculos fizeram confundir, ora se atribuindo o título de deusa da Justiça a uma, ora a outra, sem se chegar a uma solução definitiva, está a justaposição dos princípios da proporcionalidade e da razoabilidade no Direito. Entretanto, no problema mitológico, parecem os estudiosos concordarem que Themis, filha de Urano e Gaia, era uma titânide, senhora das leis naturais, sendo Diké, sua filha, a deusa da Justiça, representada segurando numa mão a espada e noutra a balança. ${ }^{18}$

No âmbito jurídico, sobretudo em países de identidade jurídica fragmentária como o Brasil, a importação assistemática de institutos do direito alienígena corrobora com os embaraços teóricos, ocasionados muitas vezes pela inserção forçada do direito comum anglo-saxônico dentro do direito civil romano-germânico. Isso tudo conduz a um entrave epistemológico e a tentativas insólitas de aparar as arestas entre esses dois princípios citados, porque carentes de uma visão sistêmica contemporizada, que analise os institutos jurídicos desde seu nascedouro, passando por suas sutilezas teóricas, até alcançar os matizes dogmáticos que a técnica demanda.

Portanto, parece claro que essas incursões doutrinárias, animadas pela cultura dos manuais, não são capazes de oferecer uma visão clara de muitos contornos do fenômeno jurídico, uma visão conceitual e pragmática que esteja amparada por uma metodologia pertinente e por um estudo crítico. No contexto deste trabalho, a confusão entre os princípios da proporcionalidade e da razoabilidade é nosso primeiro obstáculo.

Neste sentido, pretendemos ir de encontro a um pensamento dogmático de superfície, preocupado unicamente em expor teorias, apresentar conceitos e oferecer mecanismos técnicos, sem penetrar com afinco nos rincões da evolução

$18 \mathrm{Na}$ Idade Média, artistas alemães colocaram a venda em seus olhos como forma de zombaria e de denúncia dos julgamentos arbitrários da época. Posteriormente, os olhos vendados de Diké passaram a simbolizar a imparcialidade da Justiça. 
histórico-cultural do pensamento jurídico e na necessária separação científica entre sistemas jurídicos diferentes.

O estudo encabeçado nesta seção coloca no mesmo nível de relevância a análise histórica e teórica dos institutos do Direito e o exame doutrinário, geral e casuístico tão caro à dogmática jurídica. Nosso trabalho enfatiza a zetética, por ser imperativo e primordial o levantamento de questões e de problemas, perseguindo uma lógica perquiritiva, preocupado em ressaltar a necessidade de se repensar o aparentemente óbvio.

Assim, quando apontamos a necessidade de um direcionamento outro, evidentemente perpassa pelo cerne da investigação engendrada a questão metodológica. São mediocridades metodológicas que tornam míope o pensamento acerca da questão levantada, acomodadas na mesmice, preferindo uma solução intermediária de aproximar os princípios da razoabilidade e da proporcionalidade, tanto no que concerne à origem quanto à aplicação a uma definição categórica. Deixa-se de lado séculos de transformações históricas de sistemas jurídicos autônomos, acolhe-se uma mescla conceitual que não se dá nem nos domínios semânticos.

Os estudiosos do Direito não são unânimes no que se refere à questão levantada. Há aqueles que informam ser o vocábulo "razoável" oriundo de "razão" e "racionalidade", que foram vinculadas a um modelo divino, mas em seguida, a uma lógica e a uma técnica eficaz, e aos conceitos de verdade, de coerência e de eficácia. ${ }^{19}$ Mas também que, "racionalidade" e "irracionalidade" conjugam-se com a idéia de justiça e de injustiça. Os princípios da razão podem ser a forma do calcular e do pensar corretamente (lógica, metodologia), assim como o sentido do agir corretamente (prudência, retórica). ${ }^{20}$

Todavia, conforme o contexto em que esteja inserido o discurso jurídico adotado, as expressões "razoável" e "razoabilidade", podem representar: a) um enunciado jurídico, como uma norma, um princípio ou uma definição; b) um agente jurídico (o legislador, o juiz, etc.); c) um ato consistente em estabelecer, interpretar ou aplicar enunciados jurídicos; e, d) o próprio ordenamento jurídico. ${ }^{21}$

A razoabilidade tem sua origem no pensamento jurídico da tradição inglesa. $\mathrm{O}$ direito inglês é um sistema aberto, no qual as fontes do direito ora se misturam

19 PERELMAN, Chïm. Le raisonnable et le déraisonnable en droit: au-déla du posistivisme juridique. Paris: LGDJ, 1984, 19;

20 FERRAZ JUNIOR, Tércio Sampaio. Introdução ao Estudo do direito: técnica, decisão, dominação. 2 ed., São Paulo: Atlas, 1996, 352

21 ATIENZA, Manuel. Para una razonable definición de razonable. DOXA - Cuadernos de filosofia del derecho. V. 4, p 192-1987, Disponible em http://www.cervantesvirtual.com/servlet/SirveObras/12837218659036051876657/cuaderno4/Doxa4_13.pdf. Acesso em: 30.03.2011. 
ora se dissociam, cabendo a quem interpreta escolher as mais pertinentes segundo as necessidades do caso. Assim, fica nítida a tônica do racionamento. A busca da fonte jurídica, seja ela um costume, uma lei ou um precedente judicial, é que impele e anima o jurista a "razoabilizar" o direito, ou seja, a nivelar, dissecar e examinar a questão, saciando o impasse com ponderação e bom senso, tornando a análise do direito nem alheia ao caso concreto, nem estrita ao legalismo da segurança jurídica, mas sim razoável.

Por essa razão, a razoabilidade se parte em três direções: como equidade, como congruência e como equivalência. Na primeira delas, a razoabilidade existe "como diretriz que exige a relação das normas gerais com as individualidades do caso concreto, quer mostrando sob qual perspectiva a norma deva ser aplicada, quer indicando em quais hipóteses o caso individual, em virtude de suas especificidades, deixa de se enquadrar na norma geral". Na segunda hipótese, a razoabilidade "é empregada como diretriz que exige uma vinculação das normas jurídicas com o mundo ao qual elas fazem referência, seja reclamando a existência de um suporte empírico e adequado a qualquer ato jurídico, seja demandando uma relação congruente entre a medida adotada e o fim que ela pretende atingir". Enfim, na terceira situação, a razoabilidade "é utilizada como diretriz que exige a relação de equivalência entre duas grandezas". ${ }^{22}$

No que tange à proporcionalidade, os autores indicam ter ela surgido como baliza do poder de polícia do Estado no direito prussiano. Esteve ligada primeiramente aos direitos e garantias fundamentais, objetivando limitar a atuação do monarca sobre seus súditos e sua interferência na liberdade individual, no contexto do liberalismo. $^{23}$

Claramente, as raízes da proporcionalidade remontam ao direito administrativo. Seu intuito central foi sempre o de limitar a discricionariedade administrativa. No entanto, trazido para o âmbito constitucional, ela assume nova roupagem, se estende a outros ramos do Direito. Boa parte dos ordenamentos jurídicos europeus consagra a proporcionalidade em nível constitucional. Assume também destaque, quando se coloca a questão da colisão entre direitos fundamentais, uma vez que os direitos fundamentais não estão dados, estando as normas de direitos fundamentais abertas e móveis. ${ }^{24}$

22 ÁVILA, Humberto. Teoria dos princípios: da definição à aplicação dos princípios jurídicos. 4 ed. São Paulo: Malheiros, 2004, p. 103

23 ALEXY, Robert, Teoria de los derechos fundamentales. Madrid: Centro de Estudios Políticos e Constitucionales, 2001

24 STEINMETZ, Wilson Antonio. Colisão de Direitos Fundamentais e Princípio da Proporcionalidade. Porto Alegre: Livraria do Advogado, 2001, p. 63 
Canotilho $^{25}$ (1999: 267) dá dois sentidos para o princípio da proporcionalidade. O primeiro sentido, ele identifica como mais geral, sendo o da proibição do excesso: evitar cargas coativas excessivas ou atos de ingerência desmedidos na esfera jurídica dos particulares. No outro sentido, batizado de proibição por defeito (Untermassverbot) existe um defeito de proteção quando as entidades sobre as quais recai um dever de proteção (Shutzpflicht) adotam medidas insuficientes para garantir uma proteção constitucionalmente adequada dos direitos fundamentais.

Da noção de proporcionalidade decorre uma necessidade de adequação entre os meios descritos na norma e os fins por ela visados. Foi Braibant ${ }^{26}$ quem acrescentou ao conceito de proporcionalidade a vinculação à situação de fato. Com isso, estabeleceu-se a relação triangular entre fim, meio e situação fática para corrigir as insuficiências da dualidade antecedente ${ }^{27}$ Destarte, na aplicação do princípio da proporcionalidade, três elementos devem ser observados: o meio, o fim e a situação de fato.

$\mathrm{Na}$ doutrina brasileira, os princípios em foco também são estudados precipuamente sob lentes administrativistas. Prepondera, entretanto, um ideal de comutação e complementaridade entres eles, mesmo quando analisados na esfera constitucional, pregando-se a fungibilidade. ${ }^{28}$ Todavia, esperamos ter sido possível delimitar esses dois princípios sob três aspectos: origem, conteúdo e aplicação.

\section{Direitos humanos}

A expressão "direitos humanos" designa comumente as prerrogativas próprias do ser humano, sendo regidas por regras; ela provém da expressão "direitos naturais do homem", compreendendo em sua origem essencialmente "as liberdades", estendendo-se progressivamente seu campo a prerrogativas de ordem social e de alcance coletivo. Assim, pode-se concluir que os direitos humanos se originaram na escola do justo natural, caracterizada pela crença em um direito universal, eterno e imutável. Nos dizeres de Paulo Nader: ${ }^{29}$

CANOTILHO, J. J. - 1999, p. 267

BRAIBANT, Gui. Le príncipe de proportionnalité. In Mélanges offerts à Marcel Waline. Paris: LGDJ, 1974, p. 299

BONAVIDES, Paulo. Curso de Direito Constitucional. 10 ed. São Paulo: Malheiros, 2000, p. 357

BARROSO, Luís Roberto. Os princípios da razoabilidade e da proporcionalidade no direito constitucional. Revista dos Tribunais, a. 6, n. 23, p. 69, abr-jun., 1998.

29 Nader, Paulo. Introdução ao Estudo do Direito. 23 ed. Rio de Janeiro: Forense, 2003, p. 367 
O raciocínio que nos conduz à ideia do Direito Natural parte do pressuposto de que todo ser é dotado de uma natureza e de um fim. A natureza, ou seja, a propriedade que compõe o ser define o fim a que este tende a realizar. Para que as potências ativas do homem se transformem em ato e com isso ele se desenvolva, com inteligência o seu papel na ordem geral das coisas, é indispensável que a sociedade se organize com mecanismos de proteção à natureza humana. Esta se revela, assim, como o grande condicionante do Direito Positivo. O adjetivo 'natural', empregado à palavra direito, indica que a ordem de princípios não é criada pelo homem e que expressa algo espontâneo, revelado pela própria natureza.

Posteriormente, com as colocações da escola histórica de Savigny, ${ }^{30}$ baseadas numa nova metodologia do direito como fruto da História humana, os direitos humanos tiveram que ser repensados, uma vez que o ideal de universalidade e imutabilidade passou a ser questionado pelos historicistas, já que incompatível com transformação intrínseca à História. Assim, os fundamentos do direito, imerso nos domínios históricos, contrastam com as pretensões universalistas, devendo este ser integrado ao contexto social e reconhecido como instável e dinâmico. ${ }^{31}$

Não há dúvida de que são cruciais duas declarações de direitos à evolução dos direitos humanos, a Declaração dos Direitos do Homem e do Cidadão da Revolução Francesa e a Declaração Universal dos Direitos Humanos de 1948, considerando-se a historicidade que os direitos humanos adquiriram. É por essa razão que Hannah Arendt ${ }^{32}$ afirma que os direitos humanos não são dados e sim construídos, destruídos e reconstruídos.

Deste modo, e lastreado nestes parâmetros, é que Norberto Bobbio formulou sua teoria geracionista dos direitos humanos. Segundo ela, há três gerações de direitos: os direitos de primeira geração (direitos da liberdade), que são as liberdades civis e políticas aclamadas, sobretudo, no contexto das revoluções burguesas.

30 SAVIGNY. Friedrich Karl Von. Metodologia Jurídica. Trad. São Paulo: Rideel, 2005.

31 AGUillar, Fernando Herren. Metodologia da Ciência do Direito. São Paulo: Max Limonad, 2003, p. 138

32 ARENDT. Hannah, As origens do totalitarismo. Trad. Roberto Raposo. Rio de Janeiro, 1979, p. 134 
Os direitos de segunda geração (direitos da igualdade), oriundos das lutas sociais, encabeçados pelas reivindicações trabalhistas por saúde, habitação e educação. E, finalmente, os direitos de terceira geração (direitos da fraternidade), mais recentes, como sendo os direitos coletivos da humanidade, estando entre eles os direitos ao patrimônio cultural, ao meio-ambiente, à paz, etc. ${ }^{33}$

Hoje, além de estarem positivados nas cartas constitucionais de muitos países, os direitos humanos dominaram o cenário internacional, motivando e mobilizando a comunidade das nações a promover sua defesa e sua consolidação, de forma que os direitos humanos deram origem ao direito humanitário.

A partir da Declaração de 1948, começa a se desenvolver o Direito Internacional dos Direitos Humanos, mediante a adoção de inúmeros instrumentos internacionais de proteção. A Declaração de 1948 confere lastro axiológico e unidade valorativa a esse campo do Direito, com ênfase na universalidade e interdependência dos direitos humanos. (PIOVESAN, 2006: 13).

Entretanto, por mais auto-justificável que a noção de direitos humanos possa ser, é preciso que exista o estado de direito (Rechtsstaat) com um Judiciário independente para garantir sua proteção e impedir possíveis atitudes tirânicas das autoridades a pretexto de defendê-los. Ou seja, sem a presença de um ente jurídico institucionalizado, a doutrina dos direitos humanos não seria mais do que simples ideais morais ou religiosos. ${ }^{34}$

Ainda nessa seara, suscita-se o problema da fundamentação filosófica dos direitos humanos. Se eles só podem se concretizar sob a guarida do estado de direito, o problema remonta às origens do estado no contrato social. A teoria do contrato social permite identificar as vantagens que os contratantes almejam ao pactuar, ao mesmo tempo em que faz nascer a questão sobre o futuro dos indivíduos após firmarem o contrato. É neste ponto que os direitos humanos entram para resolver, pois se diferenciam dos estabelecidos convencionalmente. São, pois, direitos humanos, aqueles que podem passar do estado de natureza ao estado civil quando o contrato já não pode ser denunciado. ${ }^{35}$

BOBBIO, Norberto. A era dos direitos. Trad. De Nelson Coutinho. 10 ed. Rio de Janeiro: Campus, 1992,

34 PERELMAN, Chaïm. Le raisonnaable et le déraisonnable en droit: au déla du positivisme juridique. Paria: LGDJ, 1982, p. 120

35 LUHMANN, Niklas. O paradoxo dos direitos humanos e três formas de seu desdobramento. Themis, Fortaleza, v. 3, n. 1, p. 159, 2000 


\section{Tutela jurisdicional e aplicação dos princípios}

\subsection{Tutela penal dos direitos humanos}

O estado de direito conhece, via de regra, duas espécies de tutela jurídica de direitos, a civil e a penal. São elas que dão origem aos dois grandes ramos do direito público, os processos civil e penal. Pois bem, quando se fala em tutela penal, está-se falando nas normas de direito público que identificam um bem jurídico inviolável e the cominam uma pena, e no direito subjetivo do Estado de punir o infrator. Portanto, o direito elege alguns bens jurídicos que, por sua natureza e importância, necessitam de uma tutela mais rígida, sendo esse caráter preventivo e de intimidação a maior finalidade da lei penal. ${ }^{36}$

Por assim dizer, o direito penal é aquele que discrimina e veicula a aplicação das penas. E a pena encontra seu fundamento no ideal de retribuição, no qual perpassa fundamentalmente o princípio da proporcionalidade. Aqui é preciso que se faça uma pequena digressão histórica para comentar as modalidades punitivas adotadas no curso da História.

Não é segredo que a pena capital foi a preferida de todos os soberanos ${ }^{37}$ no curso da história, seja para demonstrar poder ou para prover espetáculos às massas, principalmente quando combinada com suplícios cruéis. A sanção máxima sempre gozou de enorme popularidade, mas foi perdendo espaço na medida em que o homem passou a encarar seu semelhante com maior respeito e a procurar soluções mais humanitárias para seus problemas.

$\mathrm{Na}$ antiguidade, assim como na Idade Média, prevaleceu o princípio do Talião - "olho por olho, dente por dente" - nas punições e castigos. ${ }^{38}$ Eles tiveram, inclusive, durante muito tempo, a conotação sacra de purificação (ordálias). Através da pena morte, o indivíduo se libertava da impiedade que cometera ao deixar de cumprir suas obrigações para com os antepassados, no ritual ancestral. ${ }^{39} \mathrm{E}$, com isso, inúmeras atrocidades foram cometidas sem a menor consideração para com a dignidade humana.

O século das luzes foi, indubitavelmente, quando os princípios humanistas aflo-

36 Mirabete, Júlio Fabrini. FABRINI, Renato N. Manual de Direito Penal, 24 ed. São Paulo: Atlas, 2007, V. 1, p. 4

37 SCHECAIRA, Sérgio Salomão e CORRÊA JUNIOR, Alceu. Teoria da Pena. São Paulo: Revista dos Tribunais, 2002, 111.

38 FERRAJOLI, Luigi. Direito e Razão: teoria do garantismo penal. São Paulo: Revista dos Tribunais, 2002, p. 312.

39 COULANGES, Fustel de. A Cidade Antiga. Trad. Edson Bini. Bauru: Edipro, 2008, p. 88 
raram com maior vigor e ganharam armas na luta contra o antigo regime e tudo o que ele representava. Grandes declarações foram escritas e pensadores de vulto brilhante insurgiram nesse cenário de monumentais transformações. Inspirados em todos esses movimentos, muitos documentos foram escritos apregoando o fim da pena de morte e das penas cruéis e infamantes, baseados em seu caráter desumano, em sua inutilidade ou em sua vã ilusão de proporcionalidade e de exemplaridade. Entre eles a Declaração dos Direitos do Homem e do Cidadão.

Beccaria $^{40}$ foi a primeira voz a se levantar contra as injustiças e os abusos ocorridos nos julgamentos e nas execuções, protestando contra a crueldade das penas. Em seu célebre livro Dos Delitos e Das Penas, ele rejeita a pena de morte, já que o cidadão não entrega seu direito à vida ao Estado, por isso este não pode tirá-la. Para ele não se pode punir um crime com outro crime. Ele aponta também um motivo de ordem prática para o abandono ao apenar por morte: sua inutilidade ao Estado e à sociedade. O rigor do suplício causa impacto somente no instante da execução, não permanecendo nos corações dos homens tal qual permanece a continuada visão de um criminoso encarcerado, imprimindo na mente daqueles que a presenciam receio e cautela.

Justamente com a ascensão dos direitos humanos no cenário mundial, as penas passam a ser humanizadas e aparece a teoria do garantismo penal. Luiz Vicente Cernicchiaro e Paulo José da Costa Junior afirmam, solenemente, ser a pena de morte uma "exacerbação do poder de punir" ${ }^{41}$ e, contra todas as espécies de penas desumanas, Ferrajoli completa:

[...] acima de qualquer argumento utilitário, o valor da pessoa humana impõe uma limitação fundamental em relação à qualidade e à quantidade da pena. É este o valor sobre o qual se funda, irredutivelmente, o rechaço da pena de morte, das penas corporais, das penas infamantes e, por outro lado, da prisão perpétua e das penas privativas de liberdade excessivamente extensas. (2002: 318).

Superadas essas explanações, dar aos direitos humanos uma tutela penal significa duas coisas. Primeiro: resplandece a relevância dos bens jurídicos, por merecerem a atenção do direito penal. Segundo: exige uma correlação íntima entre as sanções a serem aplicadas e os direitos protegidos, não se podendo olvidar também os direitos dos sujeitos passivos. Assim, deve-se considerar essa tutela segundo os princípios da proporcionalidade e da razoabilidade. Também não se pode perder de vista a amplitude da tutela penal dos direitos humanos, válida tanto para indivíduos 
quanto para organizações e Estados, que venham a lesar os bens jurídicos protegidos.

Por isso, a tutela penal, aliás, qualquer tutela, mas principalmente a penal, ganha muito destaque na temática dos direitos do homem, já que as leis e tratados limitam-se muitas vezes a declará-los. Ao se cominar penas a violações de direitos humanos, deve-se utilizar a razoabilidade em caráter qualitativo e a proporcionalidade em caráter quantitativo.

A relação razoável de qualidade se opera entre a modalidade da pena e o bem jurídico tutelado. Desse modo, é preciso que haja uma adequação satisfativa entre o tipo de sanção e a modalidade de direito humano. A relação proporcional de quantidade se dá entre o montante da pena e a gravidade da lesão. Assim, a exemplo do que já ocorre no processo penal. ${ }^{42}$

\subsection{Tutela coletiva dos direitos humanos}

Agora, no que tange à tutela civil de direitos, encontramos o ideal ínsito de reparação de danos e exigência do cumprimento de obrigações. O processo civil objetiva o término do conflito com a força vinculativa que se confere à coisa julgada, ${ }^{43}$ na jurisdição contenciosa, e o reconhecimento de um direito, relação jurídica ou situação de fato através da homologação na jurisdição voluntária.

Todavia, um instrumento muito eficaz para a tutela civil de direitos humanos é a tutela dos direitos coletivos. No Brasil, essa tutela se faz principalmente através da ação civil pública, da ação popular e do mandado de segurança, além de outras ações com natureza coletiva. Esclareceremos melhor a definição dos direitos coletivos, por entendermos estarem como espécies do gênero direitos humanos.

A temática dos direitos difusos e coletivos tem suscitado grandes divagações entre os doutrinadores do Direito. Seja pela relativa novidade ou pela abrangência de questionamentos, o tema desperta profícua discussão teórica, bem como instiga os operadores do Direito na prática cotidiana, sobejamente os processualistas. Não é segredo que a processualística tem caminhado no sentido da instrumentalização do processo, ${ }^{44}$ rechaçando o formalismo barato e trazendo novas proposições como a

42 D’URSO, Flávia. Princípio Constitucional da Proporcionalidade no Processo Penal. 2 ed. São Paulo: Atlas, 2007

43 GOLDSCHMIDT, James. Princípios gerais do processo civil. Trad. Hiltomar Martins Oliveira. Belo Horizonte: Líder, 2004, p. 32.

44 DINAMARCO, Candido Rangel. A instrumentalidade do processo. 6 ed. São Paulo: Malheiros, 1998, p. 24-25 
efetividade do Direito, o acesso à Justiça e o processo coletivo.

A nova Carta Magna brasileira de 1988, já com a alcunha de Constituição Cidadã, logrou positivar em seu corpo tanto os direitos metaindividuais quanto propiciar abrigo a institutos processuais de garantia dos direitos nela previstos. Os direitos coletivos, na denominação que lhes é dada pela Lei Maior, estão distribuídos nos artigos $5^{\circ}$ e $6^{\circ}$, mas encontram-se direitos desta natureza também no título da Ordem Social, como o direito ao meio ambiente. ${ }^{45}$ Outros direitos da mesma forma coletivizados são os dos consumidores. O Código de Defesa do Consumidor em seu artigo 81 traça alguns parâmetros de tutela dos direitos transindividuais. A Constituição é solene ao garantir a defesa do patrimônio público, da moralidade administrativa, do meio ambiente e do patrimônio histórico-cultural a qualquer cidadão por meio da Ação Popular (art. 5 , LXXIII).

Pode-se dizer que os direitos chamados de coletivos em sentido amplo são relativamente novos, não em sua essência, mas no fato de terem sido e ainda estarem sendo positivados recentemente no corpo dos ordenamentos e nas cartas constitucionais das nações. Assim, é imprescindível uma explanação acerca dos mesmos. Eles se dividem em coletivos, difusos e individuais homogêneos, segundo a doutrina moderna e mais acurada. ${ }^{46}$ Atente-se para o fato de a classificação empregar aqui o termo "coletivos" em sentido estrito, pois coletivo lato sensu designaria toda a categoria abrangida pelos direitos que transcendem a individualidade da pessoa humana.

A classificação se dá com base em critérios como a transindividualidade, podendo ela ser essencial (coletivos e difusos) ou acidental (individuais homogêneos) decorrente apenas da lei ou da situação fática. Outro fator é a indeterminação dos sujeitos, característica intrínseca dos direitos difusos, sendo que os coletivos e os individuais homogêneos têm sujeitos identificados ou identificáveis. Outro ponto concerne ao modo de agregação dos sujeitos. Para os interesses difusos, nunca há uma relação jurídica base, apenas uma situação de fato, como ocorre com os individuais homogêneos. Os sujeitos de direitos coletivos estão ligados por uma situação jurídica.

De forma sintética, pode-se inferir que os difusos, nessa divisão, seriam aqueles direitos transindividuais indivisíveis em que não é possível identificar uma coletividade específica. Os coletivos seriam também indivisíveis, no entanto, pode-se delimitar uma coletividade abrangida por eles, como os moradores de um bairro, ou a

46 LENZA, Pedro. Teoria Geral da Ação Civil Pública. São Paulo: RT, 2003, p. 60 
categoria dos metalúrgicos. Por fim, os individuais homogêneos seriam aqueles que transcendem a esfera individual, contudo, guardam caráter de divisibilidade, como o que acontece no litisconsórcio simples.

Assim sendo, a defesa civil dos direitos humanos ganhou relevo com a sua categorização em direitos coletivos, trazendo vantagens como a defesa conjunta dos vitimizados, a eficácia erga omnes das sentenças quando procedentes ${ }^{47}$ e possibilidade de substituição processual quando patrocinados por órgãos públicos (Ministério Público, Defensoria) ou entidades de classe e associações.

No meio processual coletivo, a razoabilidade tem por finalidade orientar os aspectos materiais da tutela de direitos humanos materializados em difusos e coletivos, evitando que as partes possam prejudicá-los e ajudar o magistrado a conciliar o choque entre interesses individuais e coletivos na lide. A proporcionalidade aparece como paradigma no momento da execução das sentenças e na fixação das indenizações, além de coibir excessos.

\section{Conclusão}

Resta finalizar este artigo reiterando a importância da tutela penal e da tutela coletiva dos direitos humanos serem realizadas com cautela e acuidade. Se no direito em geral uma decisão errônea é pior que a falta dela, no âmbito dos direitos humanos esse problema se assoma. Quando se aproxima dos direitos do homem, sobretudo no contexto internacional, a tutela jurídica penal, a temática fica ainda mais delicada, assumindo novas dimensões ao se deparar com a autodeterminação dos povos, a dignidade da pessoa humana, o multiculturalismo, a soberania nacional, os conflitos internacionais e os interesses de blocos econômicos. E, no contexto nacional, a tutela jurisdicional coletiva pode representar a saída para defesa civil dos direitos humanos, uma vez que possui abrangência maior e permite aos órgãos públicos e às entidades atuarem em seu nome.

47 GRINOVER, Ada Pellegrini. Direito Processual Coletivo: aspectos gerais. In GRINOVER, Ada Pellegrini (coord.) et al. Direito Processual Coletivo e o Anteprojeto Brasileiro de Processos Coletivos. São Paulo: RT, 2007, p. 14 


\section{Referências bibliográficas}

AGUILLAR, Fernando Herren. Metodologia da Ciência do Direito. São Paulo: Max Limonad, 2003.

ALEXY, Robert. El concepto y la validez del derecho. Barcelona: Gedisa, 2004

. Teoría de los derechos fundamentales. Madrid: Centro de Estudios Políticos y Constitucionales, 2001.

. On the structure of legal principles. In Ratio Juris. v.13. n. 3. Setembro, 2000.

ARENDT, Hannah. As origens do totalitarismo. Trad. Roberto Raposo. Rio de Janeiro, 1979.

ATIENZA, Manuel. Para una razonable definición de razonable. DOXA - Cuadernos de filosofía del derecho, v. 4, p. 192, 1987. Disponível em: http://www.cervantesvirtual.com/servlet/

SirveObras/12837218659036051876657/cuaderno4/Doxa4_13.pdf. Acesso em: 30.03.2011.

ÁVILA, Humberto. Teoria dos princípios: da definição à aplicação dos princípios jurídicos. 4. ed. São Paulo:

Malheiros, 2004.

BARROSO, Luis Roberto. Os princípios da razoabilidade e da proporcionalidade no direito constitucional.

Revista dos Tribunais, a. 6, n. 23, p. 69, abr-jun. 1998.

BECCARIA, Cesare. Dos Delitos e Das Penas. São Paulo: Martin Claret, 2007.

BOBBIO, Norberto. A era dos direitos. Trad. Carlos Nelson Coutinho. 10. ed. Rio de Janeiro: Campus, 1992.

BONAVIDES, Paulo. Curso de direito constitucional. 10. ed. São Paulo: Malheiros, 2000.

BRAIBANT, Gui. Le principe de proportionnalité. In: Mélanges offerts à Marcel Waline. Paris: LGDJ, 1974. CERNICCHIARO, Luiz Vicente; COSTA JUNIOR, Paulo José da. Direito Penal na Constituição. 3. ed. São Paulo: Revista dos Tribunais, 1995.

COUlAngES, Fustel de. A Cidade Antiga. Trad. Edson Bini. Bauru: Edipro, 2008.

DINAMARCO, Candido Rangel. A instrumentalidade do processo. 6 ed. rev. e atual. São Paulo: Malheiros, 1998.

D’URSO, Flávia. Princípio Constitucional da Proporcionalidade no Processo Penal. 2. ed. São Paulo: Atlas, 2007.

DWORKIN, Ronald. Levando os direitos a sério. Trad. Nelson Boeira. São Paulo: Martins Fontes, 2002. Uma questão de princípio. São Paulo: Martins Fontes, 2001.

FERRAJOLI, Luigi. Direito e Razão: teoria do garantismo penal. São Paulo: Revista dos Tribunais, 2002.

FERRAZ JR., Tércio Sampaio. Introdução ao estudo do direito: técnica, decisão, dominação. 2. ed. São Paulo: Atlas, 1996.

GOLDSCHMIDT, James. Princípios gerais do processo civil. Trad. Hiltomar Martins Oliveira. Belo Horizonte: Líder, 2004.

GRINOVER, Ada Pellegrini. Direito Processual Coletivo: aspectos gerais. In: GRINOVER, Ada Pellegrini (coord.) et al. Direito Processual Coletivo e o Anteprojeto Brasileiro de Processos Coletivos. São Paulo: RT, 2007.

HABERMAS, Jürgen. Direito e Democracia: entre facticidade e validade. Rio de Janeiro: Tempo Brasileiro, 1997.

LARENZ, Karl. El Derecho Justo: fundamentos de ética jurídica. 2. ed. Madrid: Civitas, 2002.

LENZA, Pedro. Teoria Geral da Ação Civil Pública. São Paulo: RT, 2003.

LUHMANN, Niklas. O paradoxo dos direitos humanos e três formas de seu desdobramento. Themis, Forta- 
leza, v. 3, n. 1, p. 153-161, 2000.

MARINONI, Luiz Guilherme. Teoria Geral do Processo - curso de processo civil. São Paulo: RT, 2006. V. 1. MAXIMILIANO, Carlos. Hermenêutica e Aplicação do Direito. 11. ed. Rio de Janeiro: Forense, 1990.

MIRABETE, Júlio Fabbrini; FABBRINI, Renato N. Manual de Direito Penal. 24. ed. São Paulo: Atlas, 2007. V. 1.

NADER, Paulo. Introdução ao Estudo do Direito. 23. ed. Rio de Janeiro: Forense, 2003.

PECZENIK, Aleksander. Law, morality, coherence and truth. p. 146-176. A theory of legal doctrine. Ratio Juris, v.14, n.1, March 2001.

PERELMAN. Chaïm. Le raisonnable et le déraisonnable en droit: au-delà du positivisme juridique. Paris: LGDJ, 1984.

. The Safeguarding and Foundations of Human Rights. In: Law and Philosophy. Vol. 1, No.1, pp. 119-129. Abril 1982.

PIOVESAN, Flávia. Direitos Humanos e Justiça Internacional. São Paulo: Saraiva, 2006.

REALE, Miguel. Filosofia do direito. 20. ed. São Paulo: Saraiva, 2002.

SAVIGNY, Friedrich Karl Von. Metodologia Jurídica. São Paulo: Rideel, 2005.

SCHECAIRA, Sérgio Salomão e CORRÊAA JUNIOR, Alceu. Teoria da Pena. São Paulo: Revista dos Tribunais, 2002.

SCHELER, Max. A reviravolta dos valores. Trad. Marco Antonio dos Santos Casanova. Petrópolis: Vozes, 1994.

SILVA, José Afonso da. Direito Constitucional Positivo. 23 ed. São Paulo: Malheiros Editores, 2003.

STEINMETZ, Wilson Antônio. Colisão de Direitos Fundamentais e Princípio da Proporcionalidade. Porto Alegre: Livraria do Advogado, 2001.

VILLEY, Michel. O direito e os direitos humanos. Trad. Maria Ermantina de Almeida Prado Galvão. São Paulo: Martins Fontes, 2007. 